\title{
Development of the combustion chamber of a reference calorimeter by numerical analysis
}

\author{
E. Eduardo Gonzalez ${ }^{1}$, Alejandro Estrada ${ }^{1}$, Leonel Lira ${ }^{2}$ \\ ${ }^{1}$ Instituto Tecnológico de Celaya, Antonio Garcia Cubas 600, Av. Tecnológico C.P.38010, Guanajuato, México \\ ${ }^{2}$ Centro Nacional de Metrología, km 4.5 carretera a los Cués C.P.76246, El Marqués Queretaro, México
}

\begin{abstract}
The present work focuses on the numerical modeling of two combustion chambers to be used inside an isoperibolic calorimeter to measure the Superior Calorific Value (SCV) from natural gas. This work shows the performance of both chambers working under the isoperibolic principle, through simulations based on Computational Fluid Dynamics (CFD). The aim of the work is to expose the performance of combustion chambers published in the literature versus another one proposed in this work, and to show how the performance of the chamber proposed in this work was improved by changing the geometry. It is checked by analyzing the temperature of burned gases at the exit of the combustion chamber.
\end{abstract}

\section{Section: RESEARCH PAPER}

Keywords: Isoperibolic calorimeter; Superior Calorific Value (SCV); Computational Fluid Dynamics (CFD)

Citation: E. Eduardo González, Alejandro Estrada, Leonel Lira, Development of combustion chamber of a reference calorimeter by numerical analysis, Acta IMEKO, vol. 4, no. 4, article 7, December 2015, identifier: IMEKO-ACTA-04 (2105)-04-07

Section Editor: Franco Pavese, Torino, Italy

Received March 23, 2015; In final form May 22, 2015; Published December 2015

Copyright: (C) 2015 IMEKO. This is an open-access article distributed under the terms of the Creative Commons Attribution 3.0 License, which permits unrestricted use, distribution, and reproduction in any medium, provided the original author and source are credited

Funding: This work was supported by Instituto Tecnológico de Celaya, México

Corresponding author: E. Eduardo González, e-mail: eli.gonzalez@iqcelaya.itc.mx

\section{INTRODUCTION}

The three main sources of fuels to generate energy around the world are petroleum with 4059, coal with 3724 and natural gas in the third position with 2906 million tons of crude oil equivalent. It is important to measure the quantity of energy contained in a sample of natural gas, or its SCV, for billing natural gas deliveries and it is commercially very important to determine this quantity of energy, because commercial transactions for natural gas are in energy units instead of volume or mass units. On the other hand natural gas is the lowest-cost source of energy and has the lowest $\mathrm{CO}_{2}$ emissions of all hydrocarbons, and probably in coming years will become the largest source of energy on the planet.

Nowadays the energy contained in any combustible gas is calculated on the base of composition via gas chromatography, supported with the standard ISO 6976 [1], where the SCV values for several pure gases are published. The SCV's in the standard ISO 6976 for pure gases were measured in 1931 and 1972. For methane, the uncertainty is specified to amount to
$0.12 \%$ [2]. Methane is the main constituent of natural gas, so measuring the value of its SCV is important because it is used in gas chromatography as a reference material for calibration. However some institutions and researchers have developed special devices to improve this uncertainty and have reduced it to approximately $0.05 \%$ [2].

Today some institutions develop their own devices to measure the SCV of methane and other gases. Some of them are: GERG (Groupe Européen de Recherches Gazières) with work from six partners [2]; LNE (Laboratoire National de Métrologie et d'Essais) in France [3] and OFGEM (Office of Gas and Electricity Markets) by Dale et al. [4].

Due to the commercial importance and the attempt to improve the uncertainty obtained by using gas chromatography supported by standard ISO 6976, CENAM (Centro Nacional de Metrología) together with the ITC (Instituto Tecnológico de Celaya) are developing a reference calorimeter to measure the superior calorific value of natural gas.

All this kinds of calorimeters devoted to measure SCV named above work very similar and operate using the 
isoperibolic principle. Some differences exist but generally all the apparatuses of this kind have the following main components:

1) The "burner", which provides and mixes the oxidizer and fuel which generates the flame. The "combustion chamber" and "heat exchanger", which maximize the heat transfer from the burned gases to the surrounding, generally water.

2) The "calorimeter vessel", which can contain any fluid, water in this work. Its function is to receive and measure the energy generated by the flame and the burned gases, as well as to maintain a homogeneous temperature in the fluid contained. The burner, combustion chamber and heat exchanger are immersed in the calorimeter vessel.

3) The "jacket", which is a further vessel enclosing the calorimeter vessel and having a temperature either uniform and constant or at least known as regards space and time [5].

The principle under which the calorimeter operates is called isoperibolic. It consists of a rise of temperature from the calorimeter vessel, containing a stirred liquid, observed while the jacket temperature is kept constant [5].

In the literature, specifically in GERG [2], LNE [3] and OFGEM [4], calorimeters have something in common, the combustion chamber. It has the same geometry: a cylindrical body with hemispherical lid. This work proposes to modify the geometry to an elliptical form of the burner, in order to increase the heat exchange and obtain a lower temperature of the burned gases. To demonstrate this, a numerical analysis was used to simulate the performance of both types of combustion chambers: the elliptical one proposed by this work and the cylindrical one with hemispherical lid found in the literature.

\section{METHODOLOGY}

\subsection{Design}

After reviewing and analysing the combustion chambers published by several researchers[2], [3], [4] it was found that they have in common a cylindrical body with hemispherical lid. However, to improve the performance in this work the geometry was modified to an elliptical chamber. We choose this geometry because the area increases in an elliptical chamber without compromising diameter and height. In this way, by increasing the heat transfer area, the temperature of the gases leaving the burner could be reduced. Figure 1 shows the combustion chamber from literature [2], [3], [4] with its heat exchanger and the elliptical chamber.

\subsection{Governing equations}

Conservation equations for steady state reacting flows are used in this paper. In our case, in order to take into account
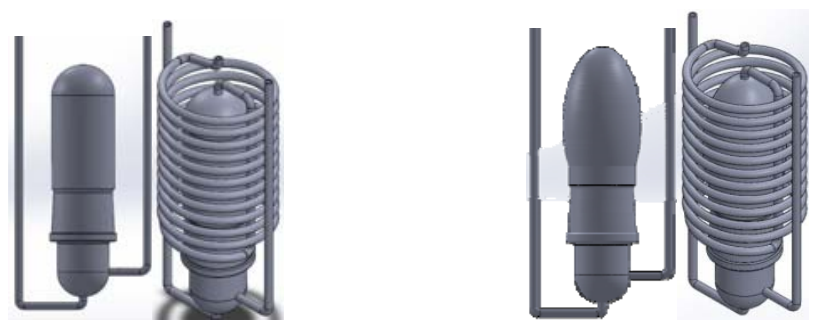

Figure 1. Combustion chamber published in the literature, left side. Combustion chamber from this work, right side. combustion, it was necessary to include chemical species in the conservation equation, therefore the code solves the conservation equation for chemical species, where the local mass fraction of each species is predicted through the solution of the convection-diffusion equation for the species, by means of the following equation:

$$
\frac{\partial}{\partial t}\left(\rho Y_{i}\right)+\nabla \cdot\left(\rho \vec{v} Y_{i}\right)=-\nabla \cdot \vec{J}_{1}+R_{i}+S_{i}
$$

where $R_{i}$ is the net rate of production of species $i$ by chemical reaction and $S_{i}$ is the rate of creation by addition from the dispersed phase. In (1) $\vec{J}_{1}$ is the diffusion flux of species $i$ that arises from the gradients of concentration and temperature. The code uses Fick's law to model mass diffusion due to concentration gradients, under which the diffusion flux can be written as:

$$
\vec{J}_{1}=-\left(\rho D_{i, m}+\frac{\mu_{\tau}}{S c_{\tau}}\right) \nabla Y_{i}-D_{T, i} \frac{\nabla T}{T} .
$$

In (2), $D_{i, m}$ is the mass diffusion coefficient for species $i$ in the mixture, and $D_{T, i}$ is the thermal diffusion coefficient. $S c_{\tau}$ is the turbulent Schmidt number (where $\mu_{\tau} / \rho D_{\tau}$ is the turbulent viscosity and $D_{\tau}$ is the turbulent diffusivity). Due to the model used for combustion, the net rate of production of species in (1) is assumed to be controlled by the turbulence with a two-step reaction mechanism:

$$
\begin{gathered}
\mathrm{CH}_{4}+1.5 \mathrm{O}_{2} \rightarrow \mathrm{CO}+2 \mathrm{H}_{2} \mathrm{O} \\
\mathrm{CO}+0.5 \mathrm{O}_{2} \rightarrow \mathrm{CO}_{2}
\end{gathered}
$$

Due to the non-premixed combustion model used, the code used solves the total enthalpy from the energy equation:

$$
\frac{\partial}{\partial t}(\rho H)+\nabla \cdot(\rho \vec{v} H)=\nabla \cdot\left(\frac{k_{t}}{c_{p}} \nabla H\right)+S_{h} .
$$

The conduction and species diffusion terms combine to give the first term on the right-hand of (3) while contribution from viscous dissipation $S_{h}$ appears in the non-conservative form. The total enthalpy $H$ is defined as

$$
H=\sum_{j} Y_{j} H_{j}
$$

where $Y_{i}$ is the mass fraction of species $j$ and

$$
H_{j}=\int_{T_{r e f, j}}^{T} c p_{j} d T+h_{j}^{0}\left(T_{r e f, j}\right)
$$

where enthalpy of formation is $h_{j}^{0}\left(T_{r e f, j}\right)$ of species $j$ at the reference temperature $T_{\text {ref, } j}$. To describe the flow of fuel and oxidant, thus buoyancy effect in the water due to large temperature gradients, the code uses the equation of conservation of momentum (6) described by

$$
\frac{\partial}{\partial t}(\rho \vec{v})+\nabla \cdot(\rho \vec{v})=-\nabla p+\nabla \cdot(\boldsymbol{\tau})+\rho \vec{g}+\vec{F}
$$

where $p$ is the static pressure, $\boldsymbol{\tau}$ is the stress tensor, $\rho \vec{g}$ and $\vec{F}$ are the gravitational body force and external body forces, respectively. 
The flow simulations were done using FLUENT. The governing nonlinear equations together with the boundary conditions are solved by an iterative numerical approach using a Finite Volume Method [6].

\subsection{Simulation Details}

Grid generation is done using ICEM. For the meshes an unstructured mesh with tetrahedral elements was used, due to the complex geometry, using elements of about $1 \mathrm{~mm}$ in dimension, approximately. In this work, two fluid domains and one solid domain were established. The first fluid domain represents the zone which provides fuel and oxidant, mixes both and generates flame and burned gases. Coupled to it, we have one solid domain, which represents the burner and the heat exchanger. The second fluid domain represents the water contained inside the calorimeter vessel, which receives all the heat due to combustion and burned gases, see Figure 2. We used default values for all thermophysical and thermochemical properties of fluids included in the code and values from literature [7] for solid properties modelling heat transfer in glass.

Both models were simulated in 3D and steady state with the same dimensions in diameter and height for both chambers, and with the same number of turns in the heat exchanger for each combustion chamber. The fuel flow is of methane, the oxidant is oxygen and its flow is three times the fuel flow [8]. The molar fractions were established to be 0.96 for methane and 0.90 for oxygen, with temperature inlet of $22.5^{\circ} \mathrm{C}$ for both. To try reproducing the physical phenomena as close as possible, the combustion chamber, burner and heat exchanger are assumed to be inside the calorimeter vessel, represented for a water volume of geometry similar to those published in the literature [2], [4]. The walls of the calorimeter vessel were set to $25.0^{\circ} \mathrm{C}$ to simulate the isoperibolic enclosure, see Figure 3.
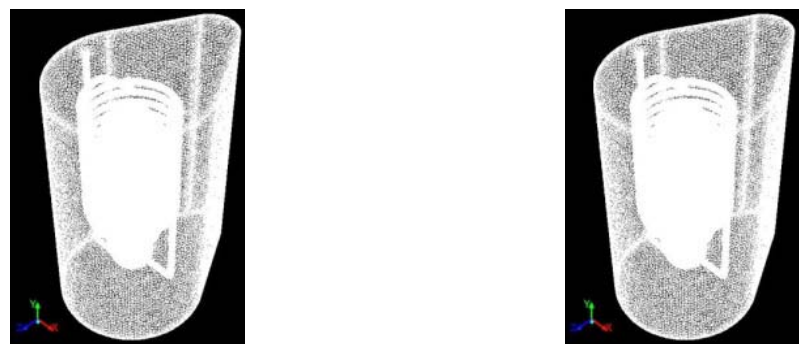

Figure 2. Discretization of calorimeter with burner, heat exchanger and combustion chamber. Right side this work with 1403244 nodes; left side from literature with 1133433 nodes.
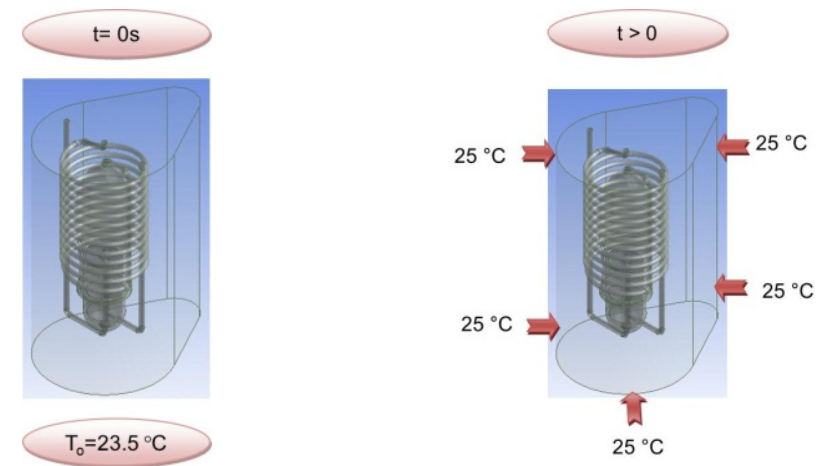

Figure 3. Sketch analysed through numerical simulation with boundary and initial conditions.
Table 1. Elliptical chamber versus cylindrical chamber.

\begin{tabular}{ccc}
\hline Schedule & $\begin{array}{c}\text { Elliptical } \\
\text { chamber }\end{array}$ & $\begin{array}{c}\text { Cylindrical } \\
\text { chamber }\end{array}$ \\
\hline $\begin{array}{c}\text { Average temperature of } \\
\text { burned gases at the exit }\end{array}$ & $30.88^{\circ} \mathrm{C}$ & $31.45^{\circ} \mathrm{C}$ \\
Average temperature of water & $29.07{ }^{\circ} \mathrm{C}$ & $29.88^{\circ} \mathrm{C}$ \\
Maximum temperature in the water & $68.27{ }^{\circ} \mathrm{C}$ & $79.89{ }^{\circ} \mathrm{C}$ \\
Minimum temperature in the water & $24.93^{\circ} \mathrm{C}$ & $24.95^{\circ} \mathrm{C}$ \\
\hline
\end{tabular}

\section{RESULTS}

The results of increasing the area of the elliptical chamber was that heat exchange increases and therefore the temperature of burned gases is lower than in the cylindrical chamber with hemispherical lid. The exterior area of the elliptical chamber exposed is $170.0 \mathrm{~cm}^{2}$. On the other hand the cylindrical chamber area is $160.0 \mathrm{~cm}^{2}$ as in Figure 4 and 5. In both figures one can see how the zones with highest temperatures are at the top of the burner. There are zones in blank, inside and in the limits of the chambers, because the temperature is higher than $40{ }^{\circ} \mathrm{C}$. The limit among the blank zone and the rest is a red ring, indicating where in the calorimeter the temperature is highest and conversely in blue where the temperature is coldest. It is useful to design the stirring system because in this zone the fluid must recirculate well to get a homogenous temperature inside the calorimeter vessel.

Table 1 shows, for the proposed chamber (see Figure 4) against the type published in literature (see Figure 5), that the average temperature of the burned gases at the exit of the heat exchanger is lower by $0.5{ }^{\circ} \mathrm{C}$ than the published one. It means an improvement of about $2.0 \%$ of the heat exchanged by the chamber proposed in this work over that in the literature. On the other hand, the average temperature of the water is similar in both cases, but is lower with the elliptical chamber by about $2.7 \%$. If we analyse the maximum and minimum temperature in the water, the cylindrical chamber has a higher temperature than the elliptical chamber.
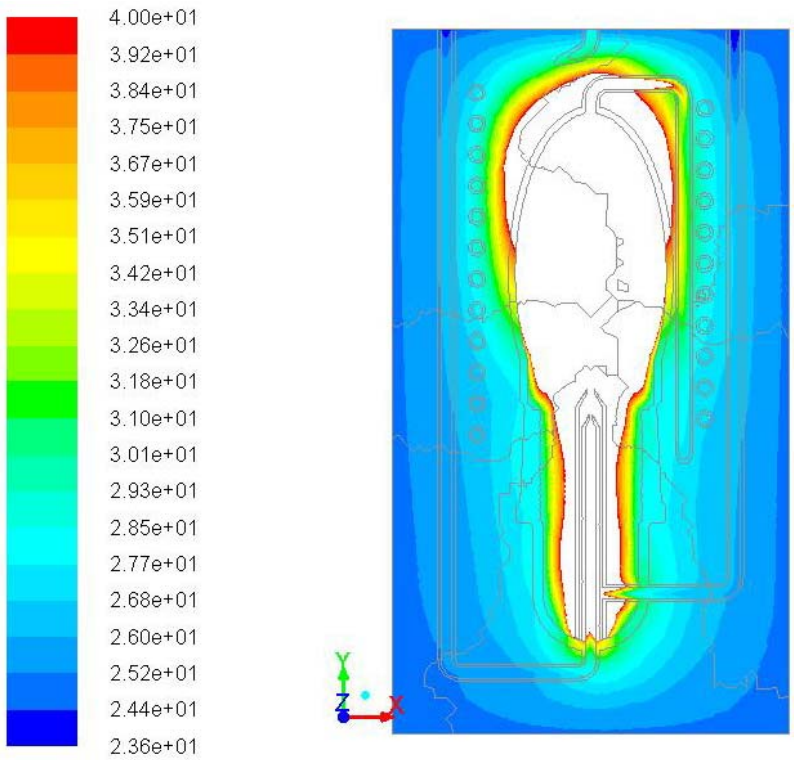

Figure 4. Temperature distribution (in Celsius). Elliptical chamber immersed in the calorimeter vessel. Area with temperatures higher than $40{ }^{\circ} \mathrm{C}$ is blank. 

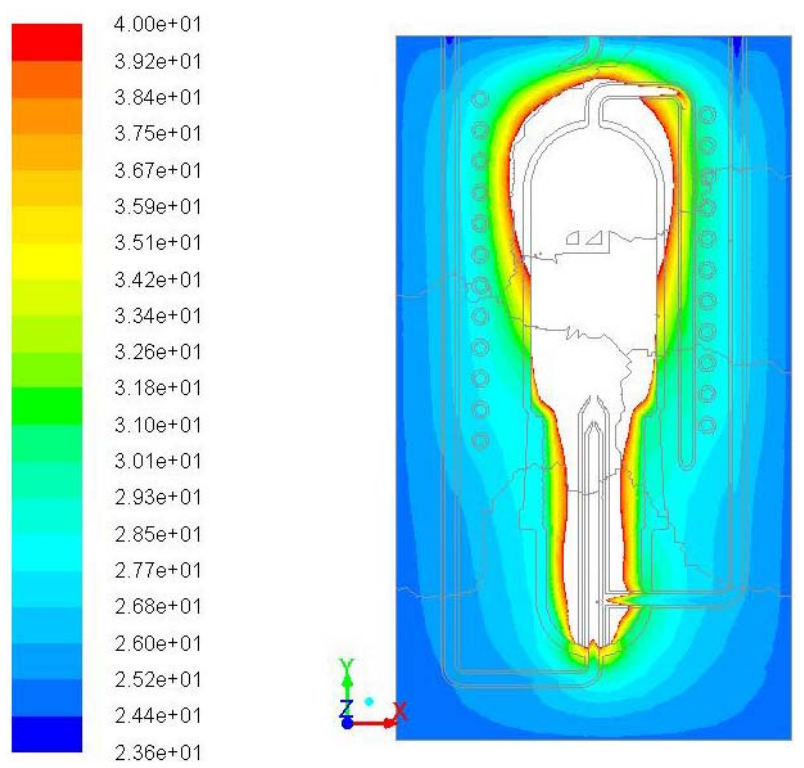

Figure 5. Temperature distribution (in Celsius). Cylindrical chamber with hemispherical lid immersed in the calorimeter vessel. Area with temperatures higher than $40^{\circ} \mathrm{C}$ is blank.

\section{CONCLUSIONS}

We have shown by numerical simulations for the steady state that the heat exchanged by the chamber proposed has improved by around $2.0 \%$ maintaining the same diameter and height for both chambers. It means that the temperature of burned gases at the exit of the heat exchanger was reduced by $0.5^{\circ} \mathrm{C}$. However we still need to validate the results obtained by numerical simulations.

Numerical simulation is useful when geometries and phenomena that govern the physical model are complicated.

Developing and evaluating both combustion chambers in the same way lead to possible generated errors that are very similar and therefore results are comparable.
We have demonstrated how numerical simulations help to develop measurement apparatuses.

\section{ACKNOWLEDGEMENT}

Every author who has contributed to the redaction and development of this work is kindly acknowledged.

\section{REFERENCES}

[1] ISO 6976, Natural Gas-Calculation of Calorific Values, Density, Relative Density and Wobbe Index from Composition. International Standard ISO 6976, 2nd edn., 1995-12-01, corrected and reprinted 1996-02-01.

[2] P. Schley, M. Bech, M. Uhring, S. M. Sarge, J. Rauch, F. Haloua, J.-R Filtz, B. Hay, M. Yakoubi, J. Escande, A. Benito, P.L. Cremonesi, Measurements of the Calorific Value of Methane with the new GERG Reference Calorimeter, Int. Journal of Thermophysics, 31:665-679 (Springer 2010).

[3] F. Haloua, B. Hay and J.-R Filtz, New French reference calorimeter for gas calorific value measurements, Journal of Thermal Analysis and Calorimetry, Vol. 97 2, 676-678, (Akadèmiai Kiadó, Budapest 2009).

[4] Andrew Dale, Christopher Lythall, John Aucott, Courtnay Sayer, High precision calorimetry to determine the enthalpy of combustion of methane, Thermochimica Acta 382, 47-54, (Elsevier 2001).

[5] Hobert C. Dickinson, Combustion calorimetry and heats of combustion of cane sugar, benzoic acid and naphthalene, Bulletin of the Bureau of Standards, (Washington 1914).

[6] Versteeg, H. K., and Malalasekera, W., An introduction to computational fluid dynamics: the finite volume method. Addison Wesley-Longman, 1995.

[7] Incropera and DeWitt. Fundamentals of Heat and Mass Transfer. Fourth edition John Wiley \& Sons.

[8] Frédérique Haloua, Jean-Noël Ponsard, Ghislain Lartigue, Bruno Hay, Clotilde Villermaux, Emilie Foulon, Murès Zaréa, Thermal behavior modeling of a reference calorimeter for natural gas, International Journal of thermal Sciences 55, 40-47, (Elsevier 2012).

[9] ANSYS® FLUENT 14.0, User's Guide. C 2011 SAS IP Inc.

[10] ANSYS® ICEM CFD 14.0, User's Guide C 2011 SAS IP Inc. 